\title{
PENILE CANCER
}

\section{TOTAL GLANS RESURFACING} VIABLE FOR ALL

Total glans resurfacing should be considered for treatment of all patients with localized penile cancer, according to the authors of a prospective study published in the Journal of Urology.

Surgical treatment of penile lesions can be detrimental to form and function and emasculating. Glans resurfacing is a less extreme surgical option for localized tumours, and involves removal of the epithelium and subepithelium and application of a skin graft. Although the technique seems promising, few studies have been published to investigate its role, and no guidelines exist from either the American Urological Association or European Association of Urology.

30 patients with glans lesions were prospectively enrolled in the study, 19 of whom underwent glans resurfacing. The International Index of Erectile Function (IIEF) questionnaire was completed at 3 months, along with a visual analogue scale (VAS) of general satisfaction.

Of the 19 patients who received glans resurfacing, 18 (94.7\%) experienced complete graft take with a median of $5 / 5$ recorded on their VAS. The patient whose graft failed was shown to have previously unrecognized dermatillomania, which led to graft breakdown. No meatal stenosis or graft infections were reported. No patient had any evidence of nodal metastases, and 1-year recurrence-free survival was $95 \%$. All patients who were sexually active preoperatively had regained sexual function at 6 months; median preoperative IIEF score was 21, compared with 22 postoperatively. $81 \%$ of men reported an improved sex life since their resurfacing and reported normal glans sensation with no evidence of sexual function.

In the largest study available to-date, these data report progression-free survival and recurrence-free survival of $100 \%$ after glans resurfacing. The authors recommend that - if the expertise is available - the technique should be considered in all patients with localized penile cancer.

Annette Fenner

ORIGINAL ARTICLE O'Kelly, F. et al. A prospective study of total glans resurfacing in localised penile cancer to maximise oncological and functional outcomes within a tertiary referral network. J. Urol. http://dx.doi.org/10.1016/j.juro.2016.12.089 (2016)

FURTHER READING Burnett, A. L. et al. Penile preserving and reconstructive surgery in the management of penile cancer. Nat. Rev. Urol. 13, 249-257 (2016) 